\section{$\underset{\substack{\text { hommes } \\ \text { \& migrations }}}{ }$}

\section{Hommes \& migrations}

Revue française de référence sur les dynamiques

migratoires

$1327 \mid 2019$

Capitales européennes et diversité culturelle

\title{
Tu mérites un amour
}

$1^{\mathrm{er}}$ film de Hafsia Herzi (France 2019)

\section{Mouloud Mimoun}

\section{Q OpenEdition \\ 12 Journals}

\section{Édition électronique}

URL : https://journals.openedition.org/hommesmigrations/10493

DOI : 10.4000/hommesmigrations.10493

ISSN : 2262-3353

\section{Éditeur}

Musée national de l'histoire de l'immigration

\section{Édition imprimée}

Date de publication : 1 octobre 2019

Pagination : 197

ISBN : 978-2-919040-47-6

ISSN : 1142-852X

\section{Référence électronique}

Mouloud Mimoun, «Tu mérites un amour », Hommes \& migrations [En ligne], 1327 | 2019, mis en ligne le 01 octobre 2019, consulté le 08 janvier 2022. URL : http://journals.openedition.org/

hommesmigrations/10493; DOI : https://doi.org/10.4000/hommesmigrations.10493 


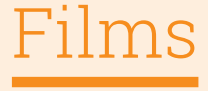

\section{Tu mérites un amour}

Film de Hafsia Herzi

(France, 2019)

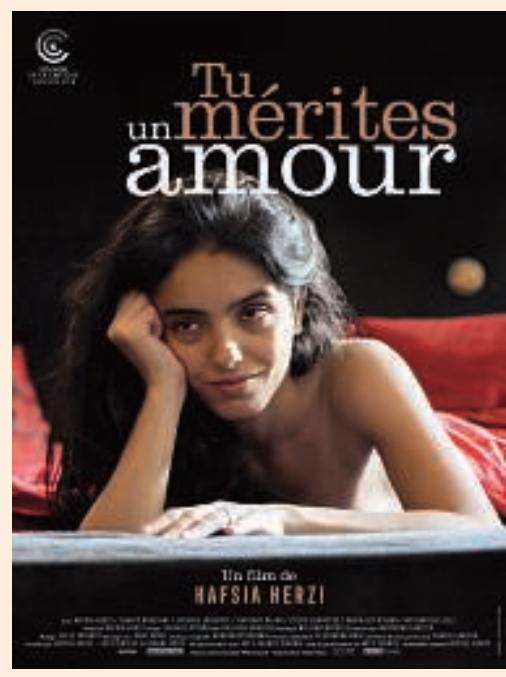

Tu mérites un amour est la toute première réalisation de Hafsia Herzi. Elle révèle d'emblée un réel talent de cinéaste qui n'est pas sans rappeler un certain Abdellatif Kechiche, son mentor de toujours, et qui la met en tête d'affiche des comédiens issus de l'immigration maghrébine (mère algérienne et père tunisien) avec La Graine et le mulet, pour lequel elle recevra le César du meilleur espoir 2008, du haut de ses 20 ans. Depuis, à 32 ans, elle a à son actif une quarantaine de films, dont les derniers - en tant que comédienne - sont Persona non grata de Roschdy Zem et Mektoub my love intermezzo, second opus d'Abdellatif Kechiche en compétition à Cannes...

L’originalité d'un film réside souvent dans son premier plan, comme dans celui-là où le personnage féminin apparaît de dos... Écoutons l'explication de la réalisatrice novice: "Je marche d'un pas décidé! On ne sait pas où, on ne sait pas chez qui, mais j'y vais. Le spectateur devine que mon personnage a dû longtemps gamberger pour avancer ainsi. Je trouve que c'était une entrée en matière assez dynamique!»

De fait, le ton est donné pour narrer cette histoire d'amour où la rupture sentimentale va générer déboires et complexité pour évoquer les relations amoureuses entre de jeunes gens. Au départ, Hafsia Herzi ne devait pas incarner le personnage de Lila, mais les conditions économiques du film en ont décidé autrement. Car il faut louer la pugnacité de la jeune cinéaste qui a totalement autoproduit Tu mérites un amour avec quelques milliers d'euros puisés dans ses deniers personnels. Tourné en quinze jours, le film a réuni techniciens et comédiens motivés et privés de cachets jusqu'à ce que sa diffusion à Cannes ait convaincu Arte de l'acheter.

Le personnage de Lila s'avère à la fois décidé et libéré, notamment au niveau de la sexualité. "Tu mérites un amour est un film dont le maître mot est liberté. Lila est libre. D'un point de vue artistique, le corps est pour moi comme un tableau. Il faut le filmer avec amour et sans tabou, sans tomber dans la vulgarité. Même quand Lila, qui tente vraiment tout sans parvenir à aller mieux, fait ce qui est pour elle l'ultime expérience, coucher avec un couple, ce qui ne la traumatise pas pour autant. Il n'y a rien de grave là-dedans. Elle ne le vit pas comme un drame. C'est la vie, c'est sa vie», conclut la jeune cinéaste.

L'autre aspect de Tu mérites un amour, c'est l'écriture cinématographique proprement dite. Autant l'approche est documentaire, autant la réalisation relève de la fiction. Les acteurs ne sont pas livrés à eux-mêmes, ils sont dans une sorte de réel et de vérité, sans doute dirigés de main de maître par Hafsia Herzi qui démontre là un talent certain dans la direction d'acteurs ce qui, pour un premier long-métrage, n'est pas forcément évident.

Nous sommes impatients de découvrir son deuxième film intitulé Bonne Mère, déjà en préparation, et qui plongera au cœur des racines marseillaises d'Hafsia pour qui la mise en scène est désormais devenue un choix prioritaire. Mouloud Mimoun 